\title{
MAPPING OF WEATHER RADAR GROUND CLUTTER USING THE DIGITAL ELEVATION MODEL (SRTM)
}

\author{
Abdenasser Djafri ${ }^{1}$ and Boualem Haddad ${ }^{2}$ \\ ${ }^{1,2}$ Image Processing and Radiation Laboratory, Faculty of Electronics and Computer \\ Science, University of Sciences and Technology Houari Boumediene. Algiers, Algeria. \\ ${ }^{1}$ a.djafri.dz@gmail.com \\ ${ }^{2}$ h_boualemehotmail.com
}

\begin{abstract}
This paper focuses on ground clutter mapping for weather radars. To achieve this, we extracted the Digital Terrain Model (DTM) using the Radio Mobile software.

We considered in this study three different weather radar sites namely, Setif (Algeria), Bordeaux (France) and Dakar (Senegal). The error observed between the simulated clutter surface by the Mobile Radio software and the one obtained in clear weather by our approach is 5.5\% for Setif, between $7.2 \%$ and $10.2 \%$ for Bordeaux and Dakar. To improve the results and due to the atmosphere inhomogeneity, we developed an algorithm based on the calculation of the curvature of the earth and considering a standard atmosphere. It is noticed that the proposed new approach, leads to $0.7 \%$ reduction in the error for the site of Setif, 3.7\% for Bordeaux and $8 \%$ for Dakar.
\end{abstract}

\section{KEYWORDS}

Radar Rainfall, Ground Echoes, DTM, SRTM.

\section{INTRODUCTION}

In early ages, humans evaluated weather conditions based on observations. To be acquainted with the atmospheric parameters involved in weather analysis and forecasting, it is necessary that such observation be, in one side, spread to the entire land surface, and on the other side, regularly performed. Generally, these requirements cannot be satisfied in uninhabited areas such as oceans, deserts, Polar Regions or high Mountains, while, in populated areas they are sources of difficulties due to the high cost of continuous human observation.

Considerable efforts have been made to automate the meteorological observation. Thus, synoptic land stations equipped with automatic sensors were created to carryout and transmit observations corresponding to the nowadays required standards. Since the sixties, continuous efforts have been made to technologically improve the performance of sounding rockets and specialized onboard instrumentation used in rockets and balloons. However, it is currently almost impossible to deal with weather observations without reporting the revolution carried out by remote sensing. Since the advent of this new technique of observation and measurement, considerable progress has been made in the analyzing and characterization of atmosphere phenomena. Nowadays, the weather radar is the most widely used instrument in weather stations around the world. Indeed, it provides a global, permanent, accurate, consistent, and rapid observation of weather phenomena both in time and space.

However, radar images are often contaminated by echoes from the earth's surface due to obstacles such as buildings, towers and reliefs. These echoes are called clutter and they are considered by meteorologists as a noise source. They reduce the ability of the radar to estimate rainfall and to identify the different types of clouds [1] [2] [3]. Various techniques to eliminate the ground 
Signal \& Image Processing : An International Journal (SIPIJ) Vol.3, No.4, August 2012

clutter from the radar images have been proposed in the literature. These are mainly Doppler techniques [4], as well as polarimeric [5] and statistics [6] [7] approaches. Note that the choice of the appropriate radar site is crucial for a good estimation of precipitations and for timely forecasting of natural disasters in order to avoid the use of filtering techniques.

The objective of this work is the mapping of ground clutter observed via weather radars by considering the geographic information. The greatest revolution of topographic mapping representation is the digital terrain model, singularly called DTM. These DTMs are increasingly used for many applications that require working with the reliefs [8] [9].

For radar applications, Lebel (1990) simulated the clutter from the ground in mountainous areas by providing a digital terrain model (DTM) based on interpolations [10]. Renard (2009) identified the clutter echoes of the Lyon region using the IGN digital terrain model with a resolution of 250m [11]. In 2010, Mesnard and Sauvageot have reproduced the distribution of ground echoes due to anomalous propagation (or anaprops) of the Bordeaux region by applying the SRTM DEM [12].

As part of this work, the Shuttle Radar Topography Mission (SRTM) was used to model the propagation of the electromagnetic radar waves. The map of the backscattered echoes due to obstacles is then extracted using the Radio Mobile software used in radiowave applications [13]. Three radar sites with different topographies were considered namely, Setif (Algeria), Bordeaux (France), and Dakar (Senegal). In addition, we developed an algorithm to efficiently simulate the radar clutter.

The rest of the paper is organized as follows: The first section covers the introduction and presents a state of the art of the topic. Section 2 describes the three studied sites. The technical characteristics of the radars, the Radio-Mobile software, and the SRTM DEMs are presented in the third section. This software was used to successfully compare its results with those obtained by our proposed approach. Therefore, the fourth section is devoted to introduce both the software and our algorithm. Results and discussions are presented in the last section.

\section{GEOGRAPHICAL PRESENTATION OF THE THREE STUDIED SITES}

\subsection{Geographical presentation of Setif region (Algeria)}

The region of Setif has an area of 6504 kilometre square, i.e., $0.27 \%$ of the whole area of Algeria. It is located between the capital "Algiers" at the west $(300 \mathrm{~km})$, Constantine at the east $(120 \mathrm{~km})$, Bejaia $(110 \mathrm{~km})$ and Jijel at the North, and at the South we find M'sila. The geographical coordinates of the city of Setif are $36^{\circ} 11^{\prime} 29^{\prime \prime}$ North latitude and $5^{\circ} 24^{\prime} 34^{\prime \prime}$ East longitude. The region of Setif is considered as the capital of the Highlands and is located at an altitude of 1300 $\mathrm{m}$. It can be divided into three main areas: A north mountainous area represented by the chain of Babors that spans hundreds of kilometres covering the north of the wilaya where we locate the high peaks of Babor Mountains that reach an altitude of $2004 \mathrm{~m}$. The centre of the region is an area of highlands at an altitude varying between 800 and 1300 meters. We find in the:

a) North: Megriss Mountains, with about $1734 \mathrm{~m}$ height (Ain Abess)

b) East: Braou Mountains, with about $1263 \mathrm{~m}$ height (Bazer Sekra)

c) South: Boutaleb Aferhane Mountains, with about $1886 \mathrm{~m}$ height (Boutaleb)

d) Centre: Youcef Aferhane Mountains, with about 1442 m high (Guedjal, Bir Hadada).

Setif region is characterized by a semi-arid continental climate with hot summers and cold winters. The average annual precipitation is about $700 \mathrm{~mm}$ in the north, $400 \mathrm{~mm}$ in the highlands and $200 \mathrm{~mm}$ in the south.

The rivers are characterized by an uneven flow due to climate data and precipitations. The main rivers are: Boussalem's river and El Kebir's river. 
Signal \& Image Processing : An International Journal (SIPIJ) Vol.3, No.4, August 2012

\subsection{Geographical presentation of Bordeaux region (France)}

The city of Bordeaux, located in the south western of France, is the capital of the Aquitaine region and the prefecture of the Gironde. In France, it is located at $498 \mathrm{~km}$ from Paris, $172 \mathrm{~km}$ from Pau, 220km from Toulouse, $108 \mathrm{~km}$ from Angoulême, 210km from Limoges, 170km from Biarritz, and $51 \mathrm{~km}$ from Arcachon. It is also distant of $202 \mathrm{~km}$ from San Sebastian (Spain).

The left bank of the Garonne, where we find the biggest part of Bordeaux city, is composed of highlands, often swampy, for example, north of Bordeaux-Lac. Although there are some hills, the average height of the bank remains very low. These plains are made up of sediment and the basement is mainly composed of gravel. The west of the city encroaches on the sandy Lands. The soils are thin, permeable to water and store heat. These soils are ideal for the practice of viticulture.

The right bank of the Garonne is very different since it passes almost directly from a plain to a limestone plateau. The elevation rises abruptly to about 90 meters. It is on this plateau, about $20 \mathrm{~km}$ from Bordeaux, that we can find world-renowned wineries such as Saint-Emilion, Pomerol and Fronsac.

The climate of Aquitaine is oceanic, characterized in Bordeaux by mild winters and hot summers. Rainfall is frequent and spread throughout the year with $820 \mathrm{~mm}$ of water and about 150 rainy days a year. In summer, rainfall is often due to thunderstorms. In July 1883, the largest rainfall ever fallen in France in 30 minutes was observed at Bordeaux.

\subsection{Geographical presentation of Dakar region (Senegal).}

Dakar is the capital of the Republic of Senegal. It is located at the western extremity of Africa, on the narrow peninsula of Cape Verde. Occupying only $0.28 \%$ of the whole country's surface, the metropolitan Dakar holds $25 \%$ of the population and concentrates $80 \%$ of country's economic activities. The city itself has over a million people and growing congestion leads to the construction of a new administrative capital.

Dakar region is located on an ancient volcano, at present; it is topped by the flagship of Mamelles, which after a long erosion, is now the rocky promontory of the Cape Verde peninsula. This promontory is surrounded by the Gorée Island in the south, the islands Madeleine in the west and in the north we have the island of Ngor. From the plateau to the suburbs of Pikine and Guediawaye, the great Dakar covers almost all the peninsula of Cape Verde. The latter is covered by non-leached ferruginous soils while the mineral soils of the dunes are recent.

Being in a tropical semi-desert, Dakar has a microclimate of coastal type, influenced by the monsoon trade winds and sea. The hot wet season extends from June to October with temperatures of about $27^{\circ} \mathrm{C}$ and a peak of precipitations in August $(250 \mathrm{~mm})$. Exceptional floods occurred in August 2005. During the dry season, which begins in November and lasts until May, the weather is a bit cooler and it rarely rains (about $1 \mathrm{~mm}$ per month).

\section{Presentation Of The USED Data}

\subsection{Presentation of the three weather radars}

\subsubsection{Technical characteristics of the weather radar of Setif (Algeria)}

The radar is installed near the town of Setif in Mount Megriss at an altitude of $1722 \mathrm{~m}$, whose geographical coordinates are $36^{\circ} 19^{\prime} 54^{\prime \prime}$ North latitude and 5²1'14" East longitude.

The radar of Setif is one of the seven radars of the Algerian meteorological network. It is associated with SANAGA (Digital Acquisition System for the Analysis of African grains), a system of acquisition and digitization of images [14]. The technical characteristics of the radar are given in Table 1. 
Signal \& Image Processing : An International Journal (SIPIJ) Vol.3, No.4, August 2012

Table 1. Technical characteristics of the weather radar of Setif region.

\begin{tabular}{|l|l|}
\hline Type of antenna & Parabolic \\
\hline Transmission frequency & $5.6 \mathrm{GHz}$ \\
\hline Transmission power & $250 \mathrm{kilowatts}$ (peak) \\
\hline Antenna gain & $30 \mathrm{dBi}$ \\
\hline Reception sensitivity & $-110 \mathrm{dBm}$ \\
\hline Spatial resolution & $1 \mathrm{~km} \times 1 \mathrm{~km}$ \\
\hline Pulse duration & $2 \mu \mathrm{s}$ \\
\hline Diameter of the antenna & $3 \mathrm{~m}$ \\
\hline Beam width at $3 \mathrm{~dB}$ & $1.1^{\circ}$ \\
\hline
\end{tabular}

The soils in the Setif region are generally of brown limestone in the south and centre, sometimes with calcareous crusts (slabs), to become clay to clay loam to and deep in the north. The soil of the Megriss Mountains, where the radar is located, is mostly composed of clay.

\subsubsection{Technical characteristics of the weather radar of Bordeaux (France)}

The radar is located in the Bordeaux-Merignac airport, whose geographical coordinates are 44 49'54" North latitude and $0^{\circ} 41^{\prime} 30^{\prime \prime}$ West longitude. The Bordeaux radar is one of 24 metropolitan France radars. The digital analysis of the reflectivity of 8 bits (SANAGA) allows processing and data storage. The radar is part of the French network (ARAMIS) managed by Météo-France. The area is almost flat. The images are largely contaminated by the ground echoes caused by the industrial area of Bordeaux in a radius of 20 to $25 \mathrm{~km}$. Table 2 gives the technical characteristics of the radar of Bordeaux.

Table 2. Technical characteristics of the weather radar of Bordeaux region.

\begin{tabular}{|c|c|}
\hline Type of antenna & Parabolic \\
\hline Transmission frequency & $3 \mathrm{GHz}$ \\
\hline Transmission power & 500 kilowatts peak \\
\hline Spatial resolution & $1 \mathrm{~km} \times 1 \mathrm{~km}$ \\
\hline Pulse duration & $5 \mu \mathrm{s}$ \\
\hline Repetition frequency & $300 \mathrm{~Hz}$ \\
\hline Beam width to $3 \mathrm{~dB}$ & $1.8^{\circ}$ \\
\hline
\end{tabular}

\subsubsection{Technical characteristics of the weather radar of Dakar (Senegal)}

The radar of Dakar is installed on a tower of 30m above the sea level at Yoff Airport, in the east of Dakar. Its geographical coordinates are $14^{\circ} 44^{\prime}$ North latitude and $17^{\circ} 29^{\prime}$ West longitude. It is operated by both the National Meteorological Office of Senegal and ASECNA (Association for the Safety of Air Navigation). This radar works only during storm periods. It also has a chain SANAGA. The average intensity of rainfalls varies from $300 \mathrm{~mm}$ to $1500 \mathrm{~mm}$ and Saint Louis to Cape Skirring [15]. The technical characteristics of the weather radar of Dakar are given in Table 3.

Table 3. Technical characteristics of the weather radar of Dakar region.

\begin{tabular}{|l|l|}
\hline Transmission frequency & $5.7 \mathrm{GHz}$ \\
\hline Transmission power & $250 \mathrm{kilowatts}$ peak \\
\hline Antenna gain & $40 \mathrm{~dB}$ \\
\hline Reception sensitivity & $-110 \mathrm{dBm}$ \\
\hline Spatial resolution & $1 \mathrm{~km} \times 1 \mathrm{~km}$ \\
\hline Pulse duration & $3 \mu \mathrm{s}$ \\
\hline
\end{tabular}


Signal \& Image Processing : An International Journal (SIPIJ) Vol.3, No.4, August 2012

\begin{tabular}{|l|l|}
\hline Diameter of the antenna & $2.5 \mathrm{~m}$ \\
\hline $3 \mathrm{~dB}$ beam width & $1.6^{\circ}$ \\
\hline
\end{tabular}

\subsection{Radio-Mobile software overview}

We used the Radio Mobile software developed by the Radio-Amateur Roger Coudé (VE2DBE) as a tool to predict the performance of a radio system. It uses digital topographic data to extract the altitude profiles linking transmitting and receiving stations. These data were added to environmental and technical parameters to supply the routines of the radio propagation model known as the "Irregular Terrain Model". The technical features of the software and the calculation parameters are given in Table 4.

Table 4. Technical specifications for calculating Radio Mobile links [13]

\begin{tabular}{|l|l|}
\hline Title & ITS Irregular Terrain Model (Longley-Rice) \\
\hline Frequency range & $20-20000 \mathrm{MHz}$ \\
\hline $\begin{array}{l}\text { Modes of } \\
\text { variation }\end{array}$ & Spot, Accidental, Mobile, Broadcast \\
\hline $\begin{array}{l}\text { Ground } \\
\text { parameters }\end{array}$ & Conductivity, Relative permittivity \\
\hline Tx power & $1.0 \mathrm{E}-8$ to $1.0 \mathrm{E}+6 \mathrm{~W}$ \\
\hline $\begin{array}{l}\text { Receiver } \\
\text { threshold }\end{array}$ & 0.01 to $2000 \mu \mathrm{V}$ \\
\hline Line loss & 0 to 500 dB \\
\hline Link Parameters & $\begin{array}{l}\text { Tx power, Tx line loss, Tx antenna gain, propagation loss, } \\
\text { Rx antenna gain, Rx line loss, Rx sensitivity }\end{array}$ \\
\hline Source type & SRTM, DTED, GTOPO, GLOBE, BIL \\
\hline Source resolution & $1 / 3,1,3$, or 30 arcsecond \\
\hline Matrix size & Up to 2000 x 2000 pixels \\
\hline Matrix coverage & Up to 5000km \\
\hline Matrix projection & $\begin{array}{l}\text { Rectangular (aligned to latitude and longitude) } \\
\text { horizontally compressed according to latitude }\end{array}$ \\
\hline Interpolation & Bi-linear \\
\hline
\end{tabular}

\subsection{Presentation of SRTM data}

The digital elevation model SRTM (Shuttle Radar Topography Mission) refers to topographic data (in the form of matrices or vectors) provided by two U.S. agencies namely, NASA and NGA (formerly NIMA). These elevation data were collected during 11days of February 2000 by the space shuttle Endeavour (STS-99) at an altitude of $233 \mathrm{~km}$ using radar interferometry.

These images cover almost $80 \%$ of the land ranging from $56^{\circ}$ South to $60^{\circ}$ North latitude. We distinguished three types:

- SRTM1: resolution of one arc second (31m at the equator), covering only the United States of America.

- SRTM3: resolution of three arc seconds (93m at the equator), global coverage.

- SRTM30: resolution of thirty arc seconds (926m at the equator), global coverage, kind of update of the GTOPO30 format.

These 16-bytes images may have the extension .Hgt (SRTM1 and SRTM3) or .Dem (SRTM30). Each MNT (SRTM1 or SRTM3) covers an area of one degree of arc side using a Universal Transverse Mercator projection (UTM) according to the World Geodetic System datum 84 (WGS-84). For DTMs, each line contains an equal number of points (3601x3601 pixels for 
SRTM1 and 1201x1201 for SRTM3). Their opening in GIS software will be in the form of a rectangular map with distorted proportions.

\subsection{Presentation of the ground clutter maps observed by the three radars in clear weather}

Figures 1.a, 1.b and 1.c represent maps of clutter observed respectively in Setif (Algeria), Bordeaux (France) and Dakar (Senegal). To extract the clutter mapping in clear weather, we analyzed 1100 images for Setif, 1200 images for Bordeaux and 900 images for Dakar. Then, we calculated the frequency of occurrence of each pixel's colour. A pointer will then determine the most frequent gray level from the first to the $262,144^{\text {th }}$ pixel $(512 \times 512)$. An image is then reconstructed representing the mapping of the ground in the study area. These images will be taken as a reference image or real map. Table 4 gives the surface of the ground echoes for each considered site.

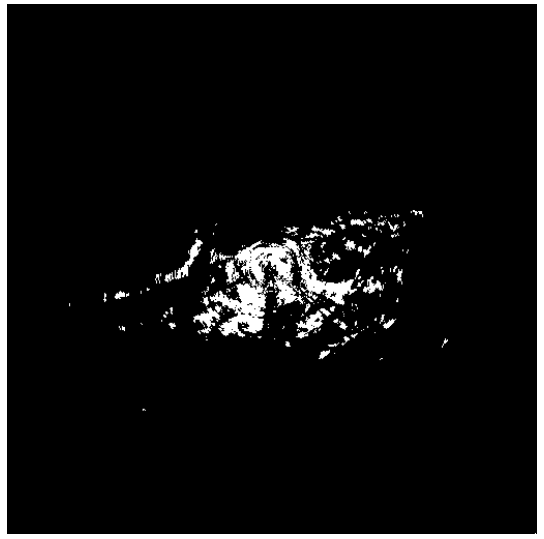

Figure 1.a. Serif's ground clutter.

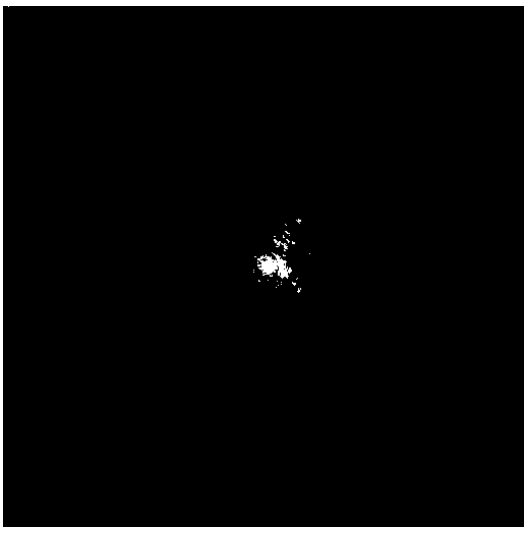

Figure 1.b. Bordeaux's ground clutter.

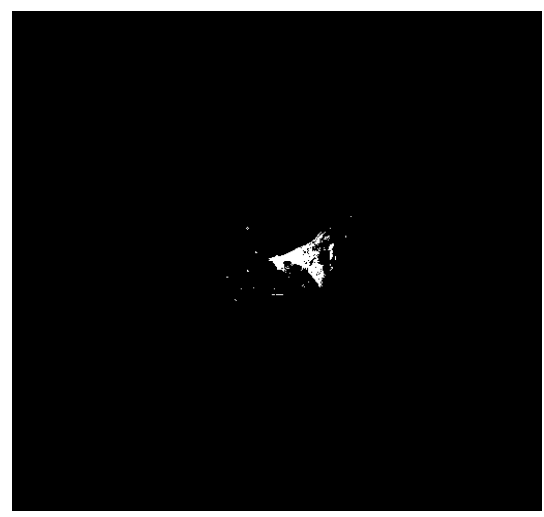

Figure 1.c. Dakar's ground clutter.

Table 5. Surfaces occupied by the ground echoes observed in Setif, Bordeaux and Dakar sites.

\begin{tabular}{|l|l|l|l|}
\hline Sites & $\begin{array}{l}\text { Setif } \\
\text { (Algeria) }\end{array}$ & $\begin{array}{l}\text { Bordeaux } \\
\text { (France) }\end{array}$ & $\begin{array}{l}\text { Dakar } \\
\text { (Senegal) }\end{array}$ \\
\hline $\begin{array}{l}\text { Echoes surface } \\
\left(\mathbf{k m}^{2)}\right.\end{array}$ & $\mathbf{6 9 7 6}$ & $\mathbf{5 7 0}$ & $\mathbf{1 0 1 2}$ \\
\hline
\end{tabular}


Signal \& Image Processing : An International Journal (SIPIJ) Vol.3, No.4, August 2012

\subsection{Extraction of the DTM}

To extract the MNT site radar using the radio-mobile software, we proceeded as follows:

a. We entered the coordinates of the radar (the centre of the map) in the menu "file" "Map Properties".

b. Enter the map dimensions in pixels and $\mathrm{km}$ as shown in figure 2. Then start the extraction.

c. Save results in a ". Map" file in the form of an array of type Integer, with 96 header bytes.

d. Finally, process the resulting matrix using development tools such as MATLAB or IDL.

Figures 3.a, 3.b and 3.c show the DTMs of the three radar sites of Setif, Bordeaux and Dakar, for an area of $512 \times 512 \mathrm{~km}$.

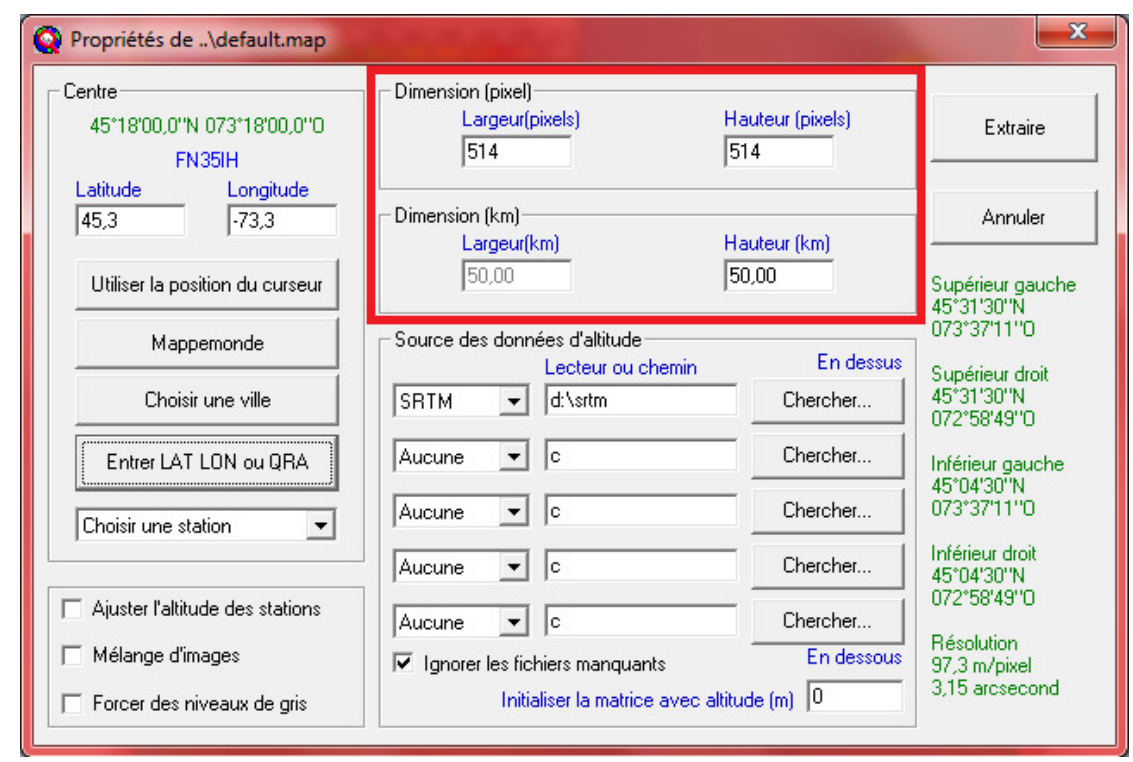

Figure 2. DTM extraction.

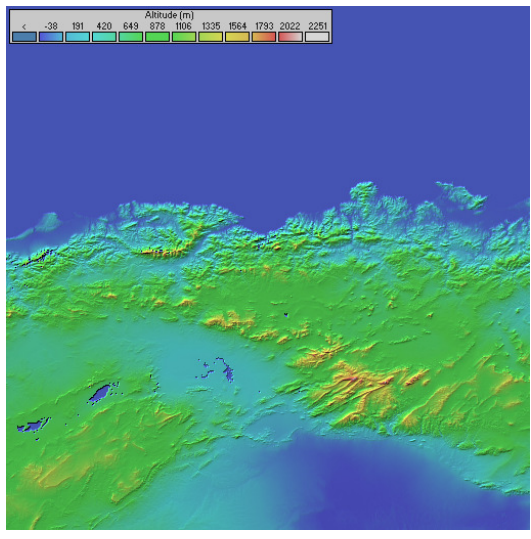

Figure 3.a. Setif's DTM

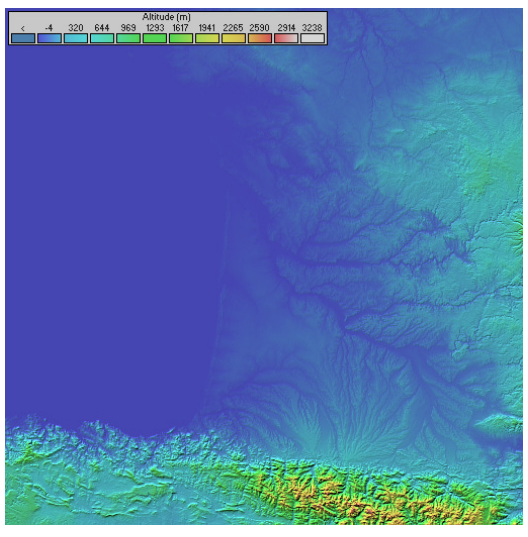

Figure 3.b. Bordeaux's DTM 
Signal \& Image Processing : An International Journal (SIPIJ) Vol.3, No.4, August 2012

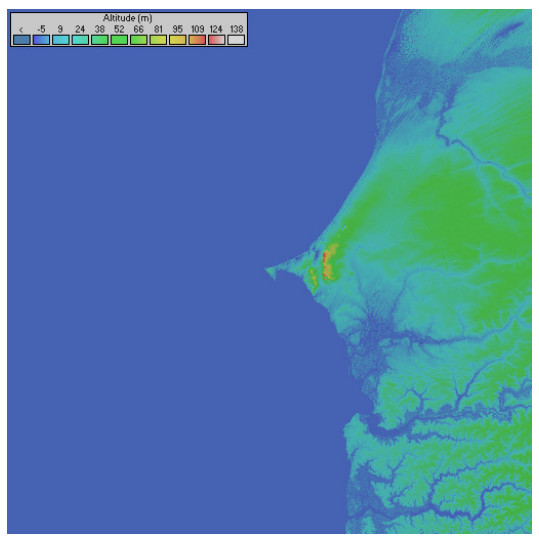

Figure 3.c. Dakar's DTM

\section{Proposed Methodology}

\subsection{Radio-Mobile Method}

To build the mapping of ground echoes from the Radio Mobile software for the three radar sites of Setif, Bordeaux and Dakar, we proceeded as follows:

a. Load the DTM of the study area (see $\S 3.5$ ).

b. Enter the maximum range given by $256 \mathrm{~km}$ and the height of the radar as shown in figure 4.

c. Draw the image. This later is then recorded and processed in MATLAB to eliminate the elevation data and to keep only the ground echoes.

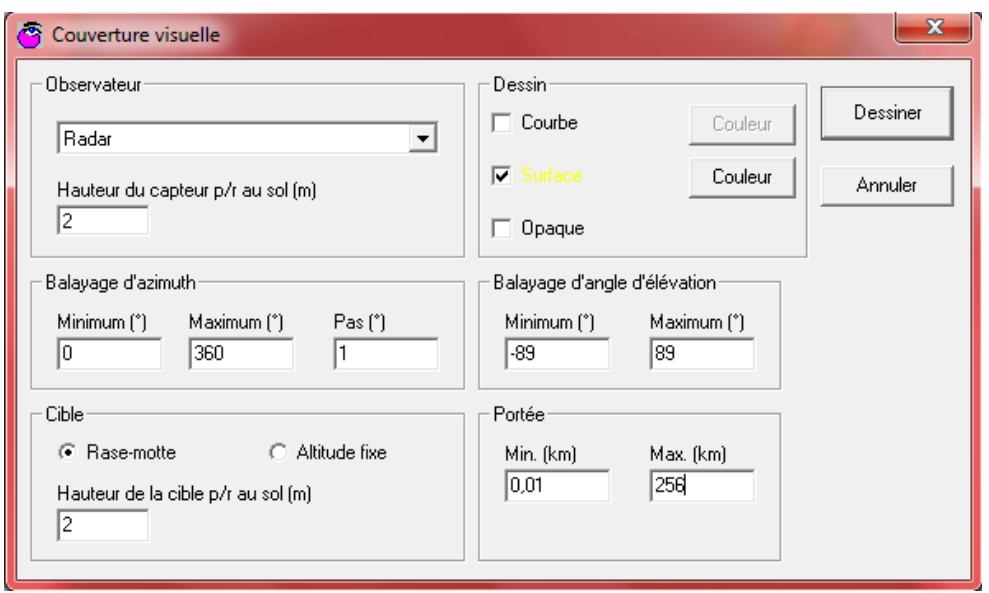

Figure 4. Optical sight routine.

\subsection{Proposed algorithm}

The approach proposed to simulate the image of the ground echoes is based on the flowchart shown in Figure 5. 


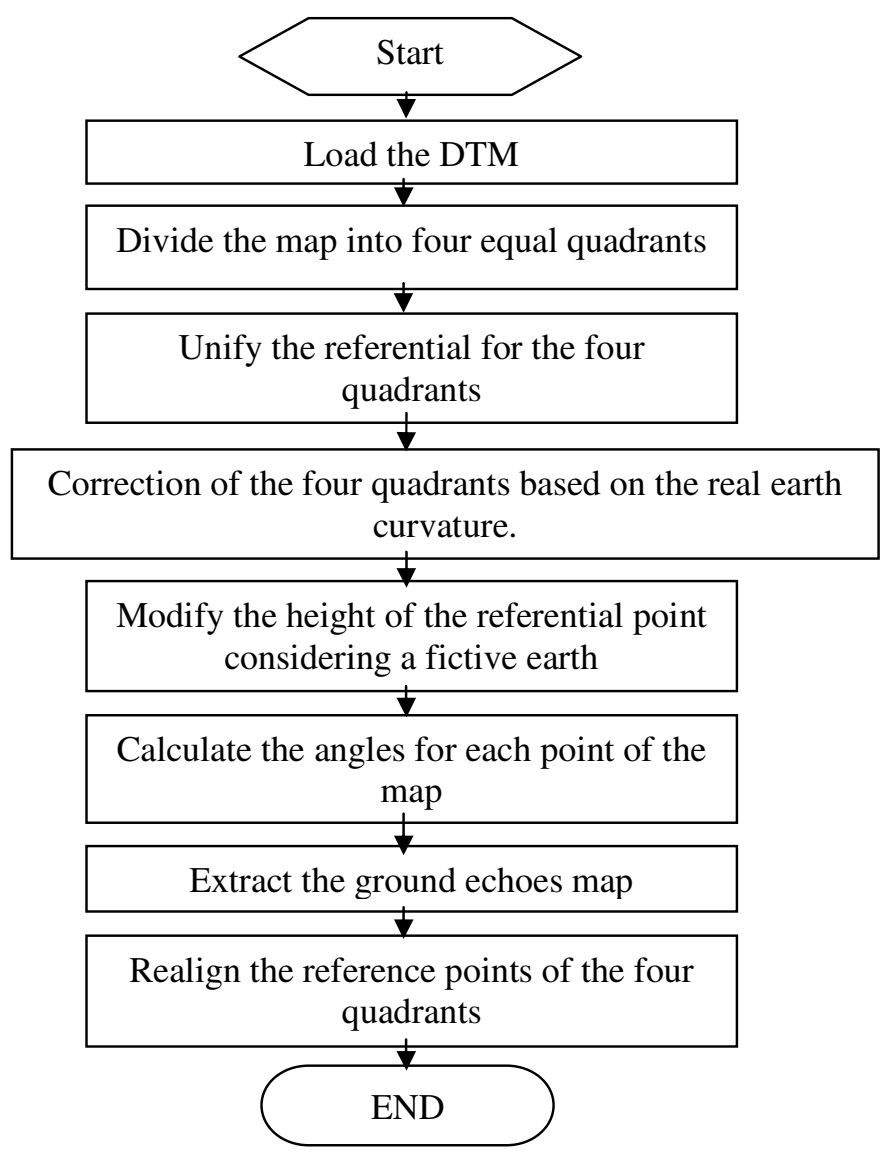

Figure 5. Algorithm of the proposed approach to simulate the ground clutter.

We will now detail each step of our algorithm.

\subsubsection{Loading the DTM}

As described in Section 3.5., the MNT extraction was achieved using the Radio Mobile software. The resulting image was processed in MATLAB and then converted to an ASCII matrix through the ENVI software.

\subsubsection{Dividing the map into four quadrants}

Dividing the image into four equal quadrants simplify scanning and avoid multiple changes of reference in order to use the same algorithm to process the entire map (Figure 6). 


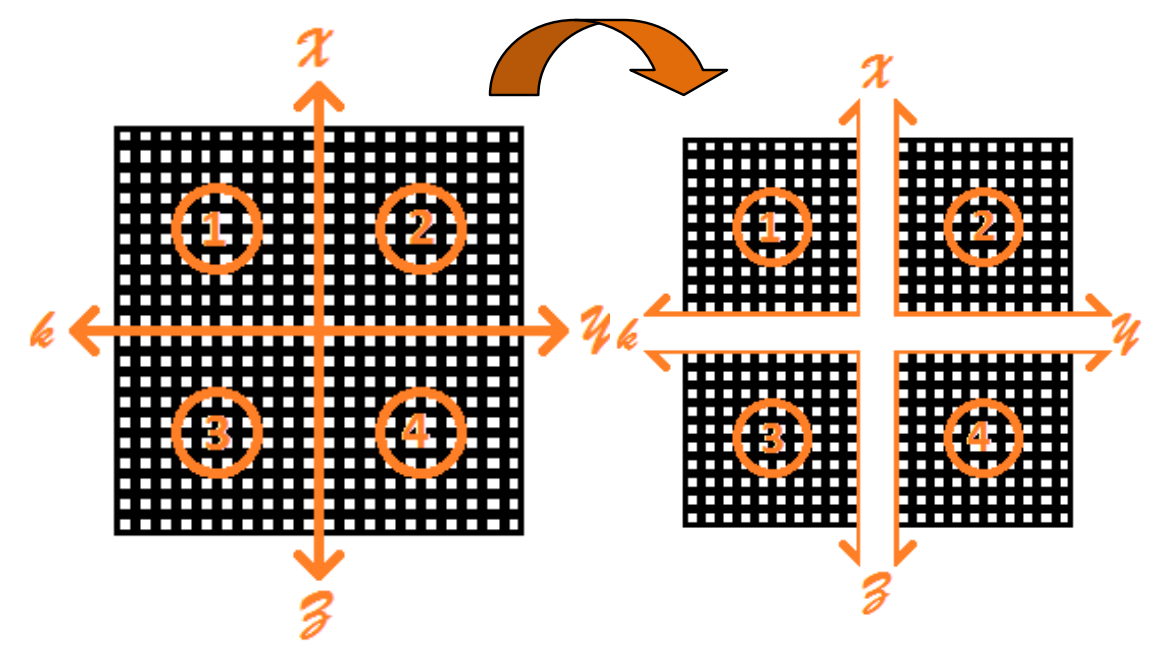

Figure 6. Dividing the map into four quadrants.

\subsubsection{Unification of the reference point}

The reference point of the DTM is the centre of the map. However, the scanning of the pixels relative to this point is a bit complicated. We performed the division of the map into four quadrants to keep the same sweep of the four quadrants relative to the reference point $(0.0)$ also, in order to process the four quadrants using the same procedure without changing the benchmark. Figure 7 shows the change of the reference frame by rotating each quadrant.

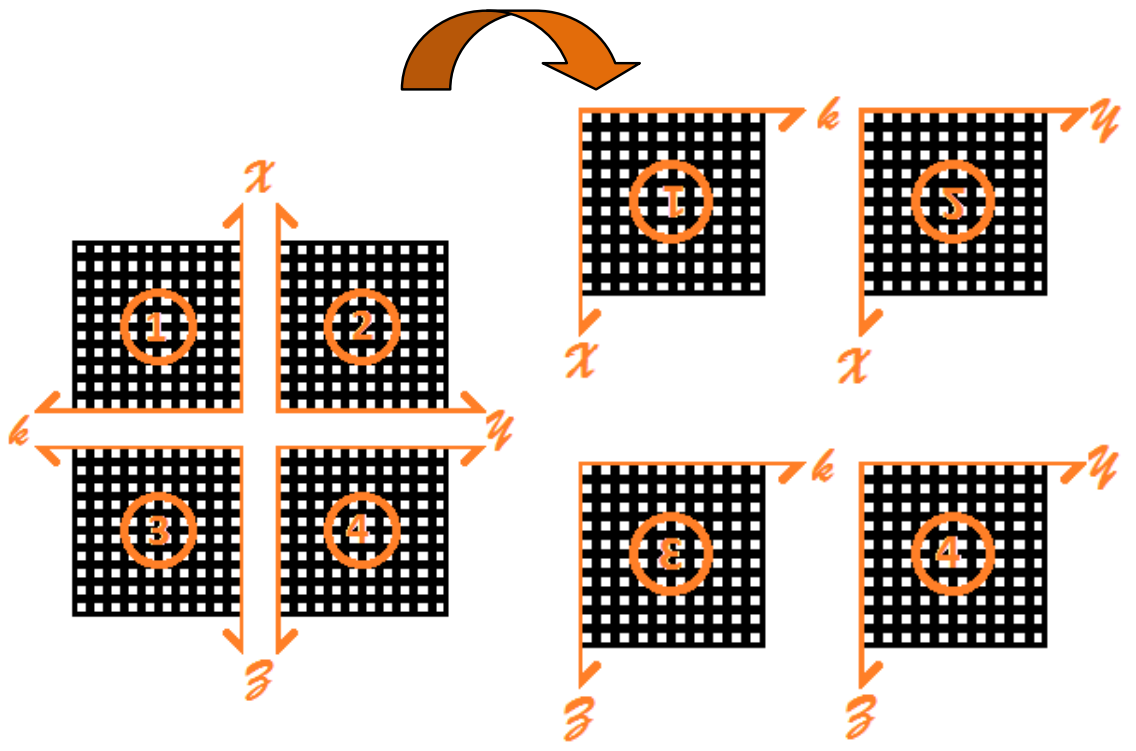

Figure 7. Pre-treatment of the simulated image.

\subsubsection{Correction of the four quadrants according to the real earth curvature}

The elevation data from SRTM maps were measured relatively to the sea level, so the land has been considered in this case as flat. Therefore, a correction to take altitudes of the earth curvature has to be made before calculating the optical range. To do so, we proceeded according to the setup shown in Figure 8: 


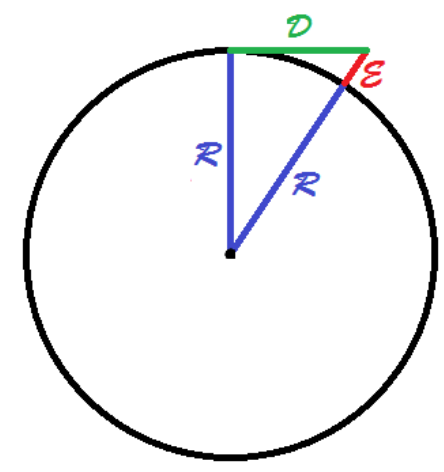

Figure 8. Calculation of the earth curvature.

Since the radius of the real earth $\mathrm{R}=6371 \mathrm{~km}$ and the distance $\mathrm{D}$ between the radar and the observation point are known, so, it is possible to subtract the following quantity $\varepsilon$, which is the correction to be made from flat ground,

$$
\varepsilon=\sqrt{R^{2}+D^{2}}-R
$$

from each pixel to get the real topographical map taking into account the earth curvature.

\subsubsection{Changing the height of the radar by considering a fictitious land}

This change is necessary because the propagation of electromagnetic waves in free space does not follow a straight path, but rather a curved path due to the atmospheric refraction defined by the law of Bouguer [16].

However, we cannot experimentally measure the different refractive indices. To remedy this, we considered a fictitious earth radius $\mathrm{R}$ ' surmounted by a homogeneous atmosphere of index n'. Let $\mathrm{h}$ be the considered altitude and $\mathrm{n}$ the refractive index of the atmosphere. The equivalence realland - fictional-land is satisfied if the relative curvature of the waves is conserved [17]. This is reflected mathematically by the expression:

$$
\frac{1}{\mathrm{R}}+\frac{\mathrm{dn}}{\mathrm{dh}}=\frac{1}{\mathrm{R}^{\prime}}
$$

For point-to-point links, we assumed a standard atmosphere defined by a gradient $\frac{\mathrm{dn}}{\mathrm{dh}}=-39 * 10^{-6} / \mathrm{km}$. The new radius of the fictional earth $\mathrm{R}$ for which the trajectory is rectilinear wave is then $8473 \mathrm{~km}$. 


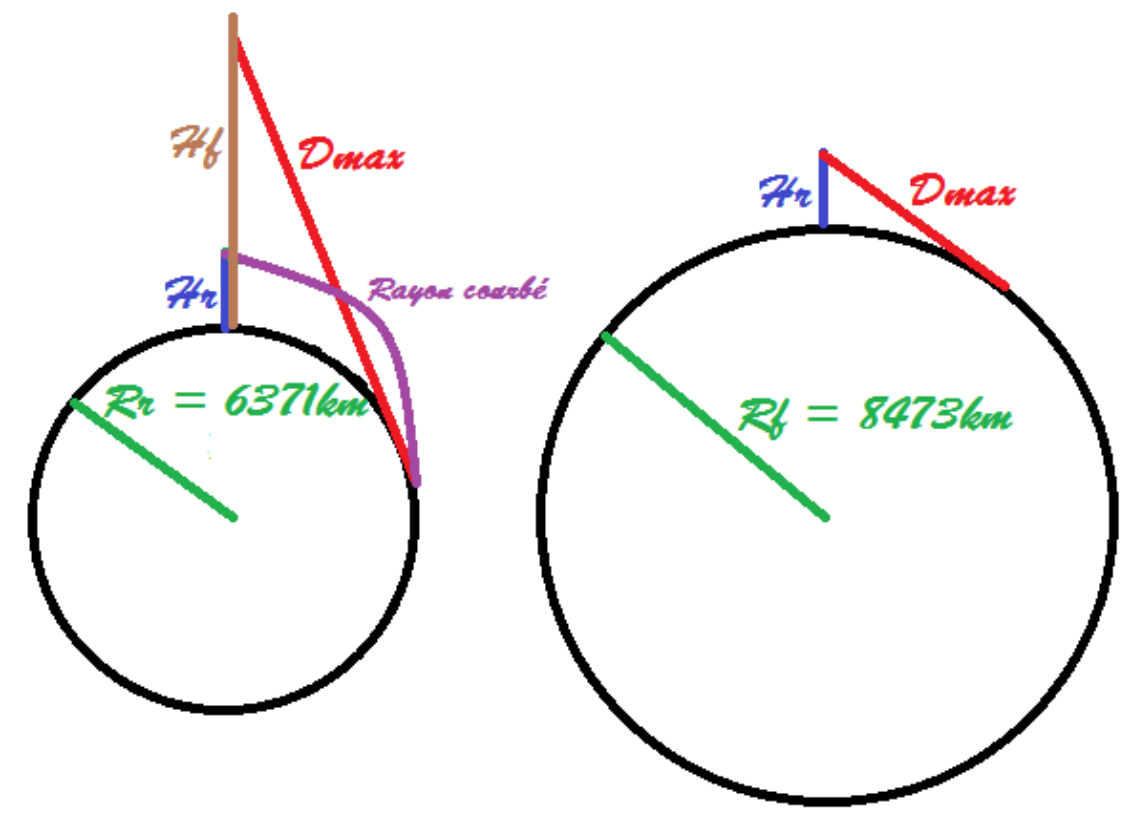

Figure 9. Illustration of the concept of changing the antenna height.

The height of the factious antenna is given by the expression:

$$
\mathrm{h}_{\mathrm{F}}=\mathrm{R}_{\mathrm{F}} \mathrm{h}_{\mathrm{R}} / \mathrm{R}_{\mathrm{R}}
$$

With:

- $\mathrm{R}=8473 \mathrm{~km}$ : radius of earth surmounted by a fictitious homogeneous atmosphere.

- $\mathrm{Rr}=6371 \mathrm{~km}$ : radius of the real earth.

- Dmax: maximum distance of the visible horizon.

- Hr: actual height of the radar antenna.

- Hf: height of the fictitious radar antenna considering the standard atmosphere.

\subsubsection{Calculation of elevation angles for each point on the map}

To each pixel of coordinates ( $i, j$ ), in the grid associated with the DTM, corresponds an angle from the radar, which tangent is written as follows (see Figure 10)

$$
\tan (\operatorname{angle}(i, j))=\frac{\text { Altitude.of.pixel }- \text { Altitude.of.radar }}{\left(\left(i-i_{0}\right)^{2}+\left(j-j_{0}\right)^{2}\right)^{1 / 2}}
$$

where $\left(\mathrm{i}_{0}, \mathrm{j}_{0}\right)$ are the radar coordinates in the DTM. 
$h r:$ Altitude of the radar above the sea level.

$h p:$ Altitude of the pixel above the sea level.

$\alpha$ : Angle de site par rapport au radar.

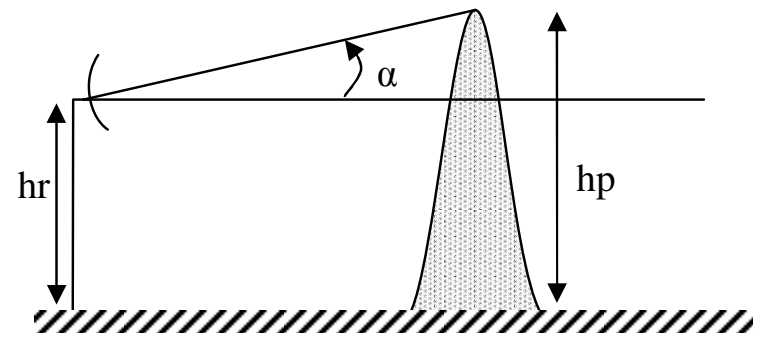

Figure 10. Representation of the viewing angle.

\subsubsection{Extraction of the ground echoes map}

Let us consider the pixel B in Figure 11. It is detected by the radar if the viewing angle is the maximum among all points between point $B$ and the location of the radar. With $\alpha_{i}$ the viewing angle of the obstacle I, two cases may occur (see Figures 12.a and 12.b)

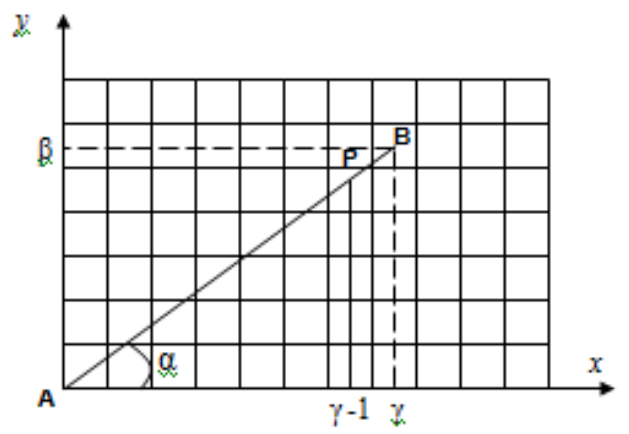

Figure 11. Azimuthally scan of the map of tangents.

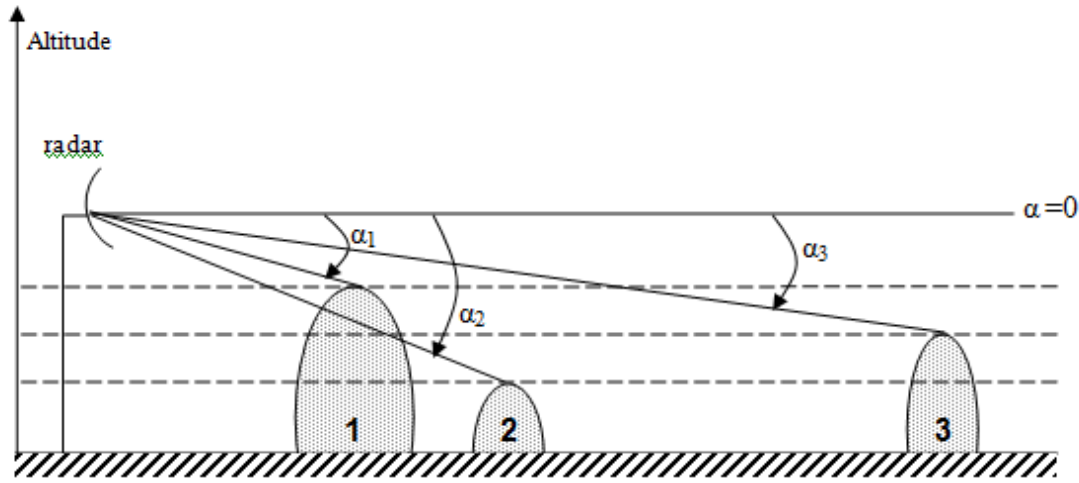

Figure 12.a. Visibility of obstacles from the radar, where the viewing angle is negative 


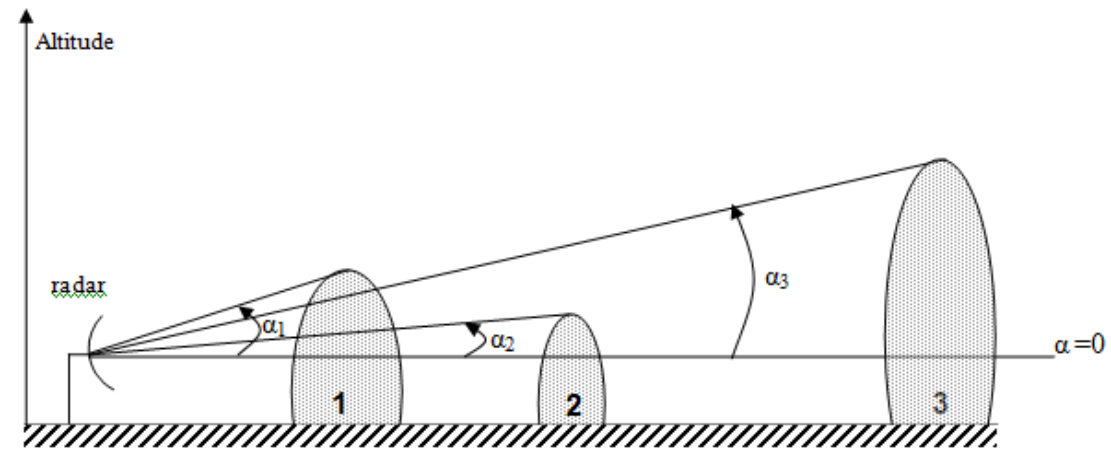

Figure 12.b. Visibility of obstacles from the radar, where the viewing angle is positive.

In Figure 12.a, it is obvious that the obstacle (3) is clearly visible on radar even if its altitude is lower than that of the obstacle (1), $\left(\alpha_{3}>\alpha_{1}\right.$, where $\alpha_{1}, \alpha_{2}$ and $\alpha_{3}$ are negative in this case). Inversely, in Figure 12.b, the obstacle (3) is the highest but it is hidden by the obstacle (1). The condition of visibility is then not assured $\left(\alpha_{3}<\alpha_{1}\right)$.

\subsubsection{Realignment of reference points}

In this step, we followed a procedure inverse to that in $\S 4.2 .3$ in order to recover the original image by performing rotations in opposite directions.

\section{RESULTS AND INTERPRETATIONS}

In this section, we present and compare the results obtained by both methods (Radio-Mobile and proposed algorithm).

\subsection{Ground echoes mapping of the region of Setif (Algeria)}

Figures 13.a, 13.b and 13.c show the mapping ground echoes of Setif obtained in clear weather, from the proposed algorithm and from the Radio Mobile software, respectively.

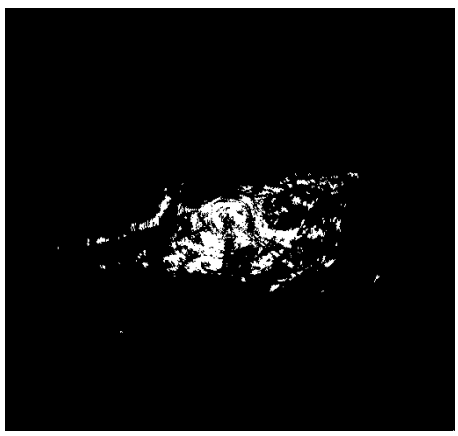

Figure 13.a. Clear weather

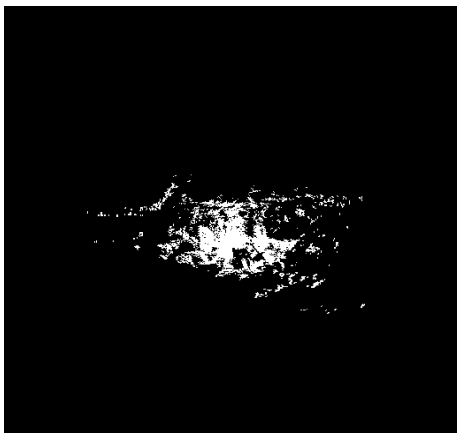

Figure 13.b. Proposed algorithm

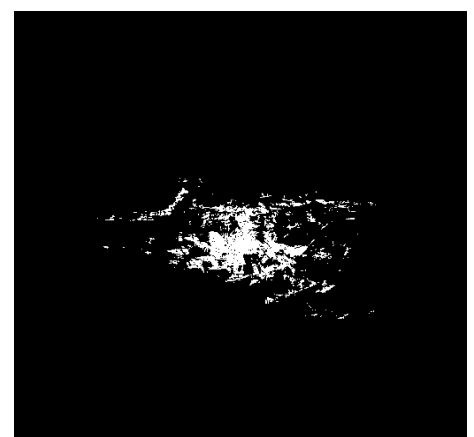

Figure 13.c. Radio Mobile

Table 6. Comparison between real and simulated ground echoes surfaces for Setif.

\begin{tabular}{|l|l|l|l|}
\hline Map & $\begin{array}{l}\text { Real } \\
\text { radar }\end{array}$ & $\begin{array}{l}\text { Proposed } \\
\text { algorithm }\end{array}$ & $\begin{array}{l}\text { Radio- } \\
\text { Mobile }\end{array}$ \\
\hline Echoes surface (km) & 6976 & 6641 & $\mathbf{6 5 9 3}$ \\
\hline Error rate & & $4.8 \%$ & $5.5 \%$ \\
\hline
\end{tabular}

As reported in Table 6, our results are acceptable since the farthest obstacle, namely the Mountains of Djurdjura, is about $80 \mathrm{~km}$. By considering a square area of $80 \mathrm{~km}$ side, we covered a surface of $6400 \mathrm{~km}^{2}$. Furthermore, if we consider other obstacles, we can easily approach these 
Signal \& Image Processing : An International Journal (SIPIJ) Vol.3, No.4, August 2012

results. Also, as the ground of Mountains of Megriss is mostly made of clay, and the resistivity of the latter is between 5 and $20 \mathrm{ohm} / \mathrm{m}$, the phenomenon of wave absorption is not very important.

\subsection{Ground echoes mapping of the region of Bordeaux (France)}

Figures 14.a, 14.b and 14.c show the mapping of ground echoes for the region of Bordeaux obtained in clear weather, from the proposed algorithm and from the Radio Mobile software, respectively.

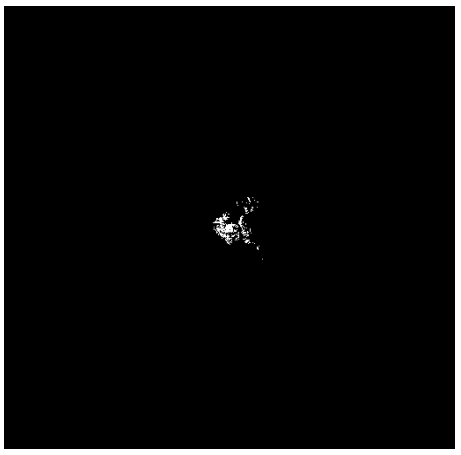

Figure 14.a. Clear weather

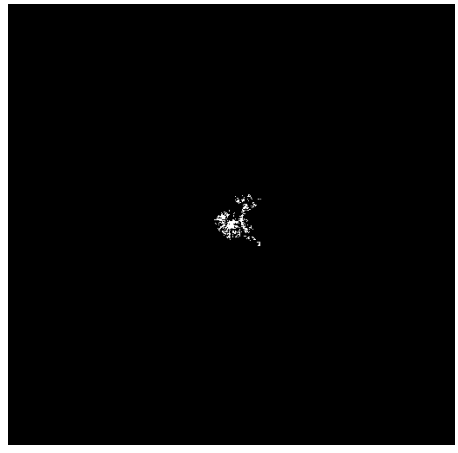

Figure 14.b. Proposed algorithm Figure 14.c. Radio Mobile

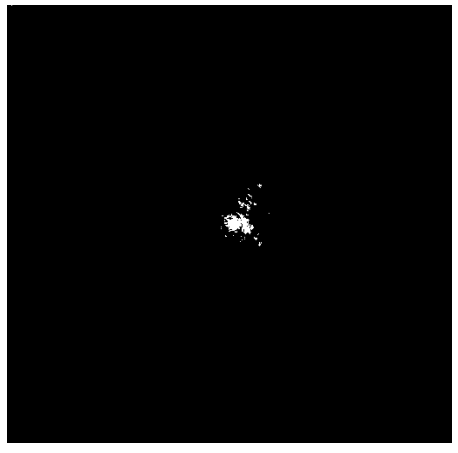

Table 7. Comparison between real and the simulated ground echoes surfaces for Bordeaux.

\begin{tabular}{|l|l|l|l|}
\hline Map & Real radar & $\begin{array}{l}\text { Proposed } \\
\text { algorithm }\end{array}$ & Radio-Mobile \\
\hline Echoes Surface $(\mathbf{k m})$ & $\mathbf{5 7 0}$ & $\mathbf{5 5 0}$ & $\mathbf{5 2 9}$ \\
\hline Error rate & & $\mathbf{3 . 5 \%}$ & $\mathbf{7 . 2 \%}$ \\
\hline
\end{tabular}

The only cause of recording clutter in this area is the industrial area located within a radius of 20$25 \mathrm{~km}$ from the radar, i.e., a square surface varying between 400 and $625 \mathrm{~km}^{2}$. This is consistent with the resulting surfaces. Similarly, the limestone that characterizes the majority of the soil of this region has a resistivity that varies in the range of $1000-5000 \mathrm{ohm} / \mathrm{m}$, thus favouring the wave attenuation.

\subsection{Ground echoes mapping for the region of Dakar (Senegal)}

Figures 15.a, 15.b and 15.c show the mapping of echoes from the ground of the site of Dakar obtained in clear weather, from the proposed algorithm and from the Radio Mobile software, respectively.

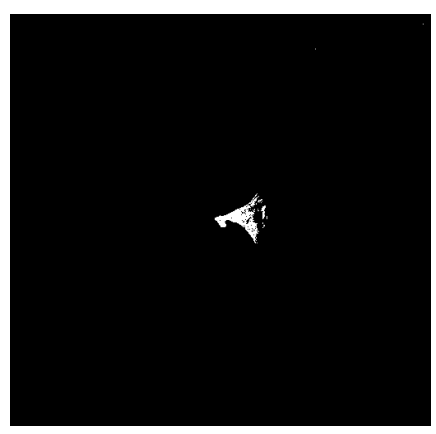

Figure 15.a. Clear weather

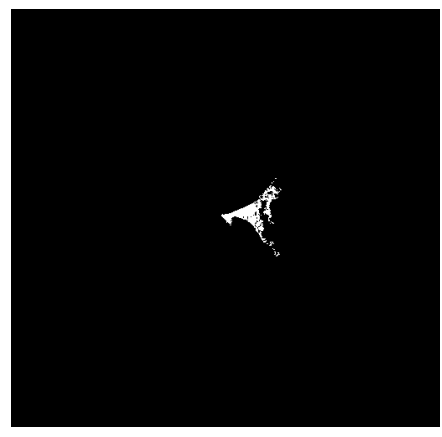

Figure 15.b. Proposed algorithm Figure 15.c. Radio Mobile

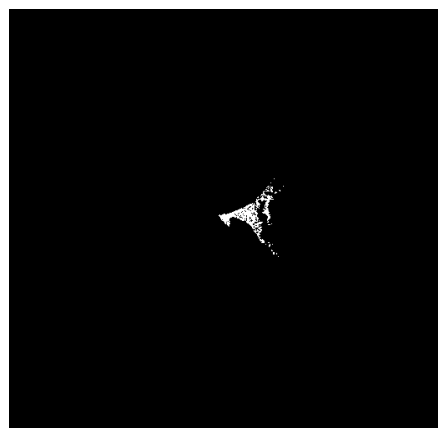

Table 8. Comparison between the real and the simulated ground echoes surfaces of Dakar. 


\begin{tabular}{|l|l|l|l|}
\hline Map & Real radar & Proposed algorithm & Radio-Mobile \\
\hline Surface echoes $(\mathrm{km})$ & $\mathbf{1 0 1 2}$ & $\mathbf{9 9 0}$ & $\mathbf{1 1 1 5}$ \\
\hline Error rate & & $\mathbf{2 . 2 \%}$ & $\mathbf{1 0 . 2 \%}$ \\
\hline
\end{tabular}

This clutter surface seems large due to the nature of the flat land. This can be justified by the expansion of the capital for economic and administrative needs. Indeed, $80 \%$ of the Senegalese population lives in this region. Urbanization can also be a cause of the reflection of electromagnetic waves. In addition, the composition of soil is ferruginous, thus increasing wave reflection.

\section{CONCLUSION}

Our work focused on the study of the ground echoes from a digital terrain model. It was shown that this method allows a simple approach to solve the problems of ground clutter. Furthermore, this geometric technique can adequately reproduce the all clutter in a given image.

We proceeded in two different ways to build the ground echoes map. First, we generated the image representing the clutter from the Radio Mobile software. Then, we proposed an algorithm that takes into account the curvature and the inhomogeneity of the atmosphere from a model of earth, topped by a fictitious homogeneous atmosphere. This approach helped reducing the error between simulated and real surfaces.

The obtained results show that in Setif, there are a considerable number of echoes from the ground even if the radar is located at an altitude of $1722 \mathrm{~m}$. This is due to the nature of terrains surrounding the radar, i.e., the Djurjura Mountains as well as the Mountains of Bibans and Babors. Comparison between the simulated map of echoes and the real-time radar image shows clearly that the error is about $4 \%$. This demonstrates the efficiency of the approach in the radar site selection since it can contribute to minimize the ground echoes and the masking effects and is valid in both meteorology and air navigation. The obtained results for the other two sites are also encouraging because the error does not exceed 4\%. For comparison, the error with the RadioMobile software can reach $10.2 \%$ as for the site of Dakar.

The expected perspectives would be to map sites with fake echoes due to anomalous propagation (or anaprops). In addition, the study of the land and its electrical properties can be used to explain the clutter distribution. Also, this can be advantageously completed by exploring different type of radar antennas as well as their radiation patterns because side lobes are the main source of ground clutter development.

\section{REFERENCES}

[1] Austin P., (1987), "Relation between measured radar re activity and surface rainfall”, Monthly Weather Review, vol. 115, p.1053-1070.

[2] Billingsley B.J., (2001), "Low angle radar land clutter . Measurements and empirical models", Lincoln laboratory, Massachusetts Institute of Technology, United Kingdom. Ed, Scitech publishing INC.

[3] Sauvageot H., (1992), "Radar Meteorology", Artech House, Boston-London.

[4] Doviak R.J., Zrnic DS, (1993), "Doppler radar and weather observation, Academic Press Incorporation", San Diego.

[5] Ryzhkov A.V., Zrnic D. S, (1998), "Polarimetric rainfall estimation in the presence of anomalous propagation”, Journal of Atmospheric and Oceanic Technology, vol. 15, p.1320-1330.

[6] Haddad B., Adane A., Sauvageot H., Sadouki L., Naili R., (2004), "Identification and filtering of rainfall and ground radar echoes using textural features “, International Journal Of Remote Sensing , vol. $25, \mathrm{~N}^{\circ} 21$, p. 4661-4656. 
Signal \& Image Processing : An International Journal (SIPIJ) Vol.3, No.4, August 2012

[7] Seltmann J.E.E., Riedl J., (1998), "Improved clutter treatment within the German radar network: first results”, COST-75 final seminar, Locarno, p.267-279.

[8] Dupont S., (1997), "Production de modèles numériques de terrain par interférométrie ROS", Thèse de doctorat, Université Nice-Sophia Antipolis.

[9] Charleux-Demargne J., (2001), "Qualité des Modèles Numériques de Terrain pour l'hydrologie”, Thèse de doctorat, Université de Marne-la-Vallée.

[10] Lebel T. (1990), "Simulation of weather radar ground clutters in a mountainous area using digitized elevation model”, Proceedings of two Lausanne symposia, August 1990. IAHS Publ. No. 193.

[11] Renard F., (2009), "La prise en compte des effets liés au relief dans la mesure du radar météorologique local de l'agglomération Lyonnaise” , Journée de Climatologie - Besançon.

[12] Mesnard, F., Sauvageot, H., (2010), “Climatology of anomalous propagation radar echoes in a coastal area”, Journal of Applied Meteorology and Climatology, vol.49, pp. 2285- 2300.

[13] http://www.cplus.org/rmw/data.html

[14] Sauvageot H., Despaux G., (1990), "SANAGA : Un système d'acquisition numérique et de visualisation des données radar pour la validité des estimations satellitaire de précipitation", Veille climatique satellitaire, vol. 31, p.51-55.

[15] Nzeukou A., Sauvageot H., (2002), "Distribution of Rainfall Parameters near the Coasts of France and Senegal”, Journal of Applied Meteorology $41: 1,69-82$

[16] Boithias L., (1984), "Propagation des ondes dans l'environnement terrestre et planétaire". Edition Dunod, Paris, 320 p.

[17] Du Castel F., (1961), "Propagation troposphérique et faisceaux hertziens transhorizon". Edition Chiron, Paris.

\begin{abstract}
Authors
Prof. Boualem HADDAD got his degree in Telecommunications Engineer from the national polytechnic school (Algeria) in 1982, his Magister degree in applied electronics in 1991 and his $\mathrm{PhD}$ degree in Atmospheric radiation from the University of Sciences and Technology of Algiers in 2000. His areas of interest are electromagnetic radiation, weather radar and instrumentation and atmospheric modeling. He served as Chairman of the scientific council of the telecommunications Department from 2003-2004 and from 2007-2010. He is also, head and member of many research projects in Atmospheric Radiation, Electronics applied to 2001, and member of Radiation and image processing laboratory.

Mr. Abdenasser DJAFRI got his bachelor's degree in Electrical Engineering from the University of Science and Technology of Houari Boumediene (Algerie) in 2008, his Master's degree in telecommunication systems in 2010 and a PhD student till now in the same university. His areas of interest are radiocommunication, weather instrumentation and technology. He served as a member state delegate in the World Radiocommunication Conference of the International Union of Telecommunications (ITU-R WRC Geneva 2012). He is also a permanent participant in the working party 5D of IMT Systems in the International Union of Telecommunications Radiocommunication's Sector.
\end{abstract}

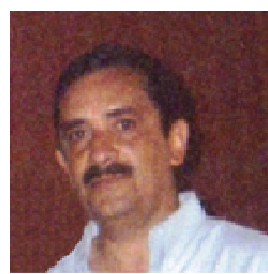
meteorology and electromagnetic radiation in the low atmosphere. He published more than 14 research Journal papers in various fields, and more than 20 research papers in national and International Scientific Conferences. He has been teaching since 1984. From 1996-1999, he was the assistant director of education and pedagogy. He is currently a professor at the University of Sciences and Technology of Algiers since

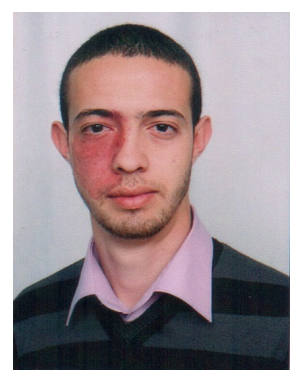

